\title{
The Cost Analysis of an Education Building through Computer-Aided Design according to Different Flooring Systems
}

\author{
Mustafa ALTIN ${ }^{1}$, Sakir TASDEMIR**2
}

\section{Accepted $15^{\text {th }}$ August 2014}

\begin{abstract}
Computer-aided Design (CAD) means that an analysis can be made in an electronic environment. As in all the sectors, its usage has reached to further levels in the construction technologies. Beginning from the architectural project, all of the related project and calculations are provided through CAD programmes. While deciding upon which construction system is used in the construction at the stage of project, it is an important subject for construction firms that projects are prepared according to different construction systems and the most appropriate cost is obtained by making quantity survey. Through today's CAD programmes, analyses were made on the same project according to different construction techniques at short notice and their quantity surveys were made in short durations and through which technique with the most appropriate cost, the construction is decided to be built. In this study, IdeCAD Structural ver 7.020 that is commonly used in Turkey as CAD programmes was used and a project of an education building was prepared in the system of framework and as normal flooring and also ribbed floor slab and separate Reinforced Concrete (RC) Static projects of the building were prepared according to the available regulations. Quantity survey of concrete, formwork, reinforcing bar belonging to both two projects and their cost analyses were made and compared. As a result of comparing, it is determined that normal flooring system can be constructed with a more affordable cost than ribbed floor slab system.
\end{abstract}

Keywords: Computer-aided Design (CAD), software, cost analysis, quantity survey, $R C$ static project.

\section{Introduction}

Engineers and designers in the field of construction have a desire of figuring out the most appropriate way and cost in structures by using minimum materials [1]. In the process, costs carry a great role in the process [2]. Determining cost is based on experiences. Construction practitioners know that there are some elements which are uncertain and affect costs. That the cost estimators perceive the factors determining the cost enable them to have more competence and thus this provides more accurate results [3].

Construction firms should realize their works with the most ideal and economical cost in order to develop projects and market the buildings they constructed. The cost analyses are dealt with at the stage of project and the most ideal functional analysis are made. While the most economic analyses are made, it is also a must that the constructions should be built according to the construction rules of earthquake-resistant. In other words, there is an obligation to construct the solid and economical buildings. Our available earthquake regulation in Turkey, "The Rules about Buildings that will be constructed in the Earthquake Zones" was issued in 2007 and it is also valid nowadays. Concrete Static projects are prepared according to the provisions of this regulation.

In this study, the static projects of an education building

\footnotetext{
${ }^{1}$ Selcuk University Higher School of Vocational and Technical Sciences, Campus, 42031, Konya/Turkey

*Corresponding Author: Email: stasdemir@selcuk.edu.tr

\# This paper has been presented at the International Conference on

Advanced Technology\&Sciences (ICAT'14) held in Antalya (Turkey),
}

consisting of the ground floor, four typical floors and penthouse and whose the school area of the ground floor is $403 \mathrm{~m}^{2}$ were prepared according to two different bearing systems and their quantity survey were determined thanks to the CAD programmer. They were multiplied by unit prices of 2013 and their costs of formwork, concrete and reinforcing bar were calculated and comparisons were made.

\section{Material and Method}

Education buildings are constructed according to different design techniques in terms of their aims of usage and places. The school in the study is a design project belonging to a high school that is thought to be constructed in a district. At the stage of design, two different analyses were made in order to find the most ideal cost at the deciding stage on whether the bearing systems of the building is constructed with the framework system as normal flooring or as ribbed floor slab. The building was considered to have the school area of $403 \mathrm{~m}^{2}$. It was designed to be organized that on the ground floor, there will be 4 floors of classes and the attic will be library and meeting room. In the education building, in total, 15 classrooms, a principal's room, two vice-principal rooms, accountant's room, a library, a canteen, multi-purpose hall, a teachers' room, meeting room and a sufficient number of toilets and sinks exist. IdeCAD Structural ver. 7.020 commonly used on the market was used in the project drawings [4]. In Figure 1, there exist a story plan belonging to the education building and in Figure 2, the front view of the building exist. 


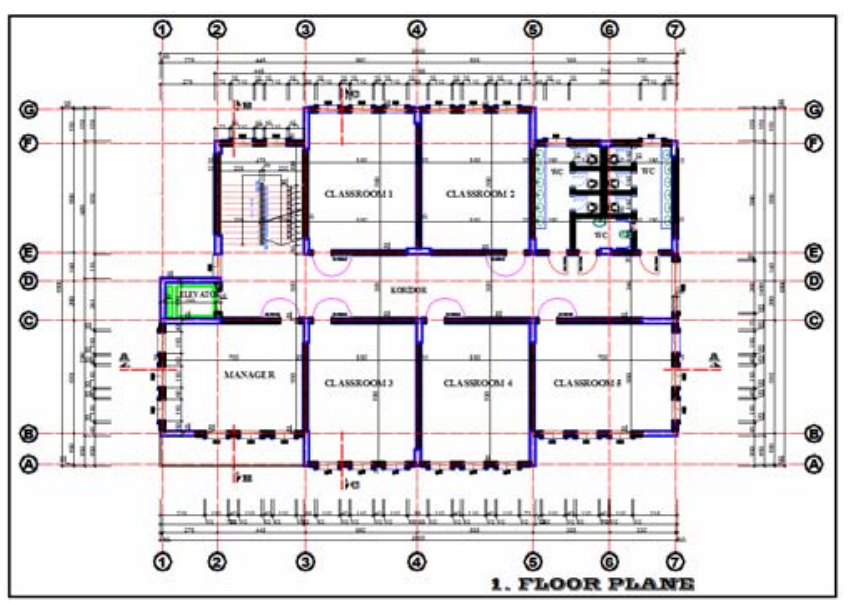

Figure 1. The floor plan belonging to the education building

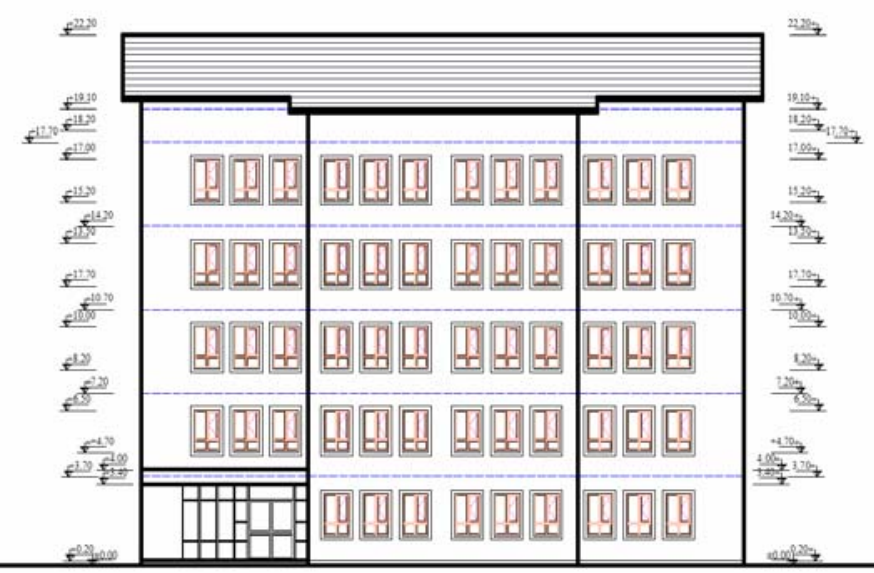

FRONTE FACADE

Figure 2. The front façade belonging to the building

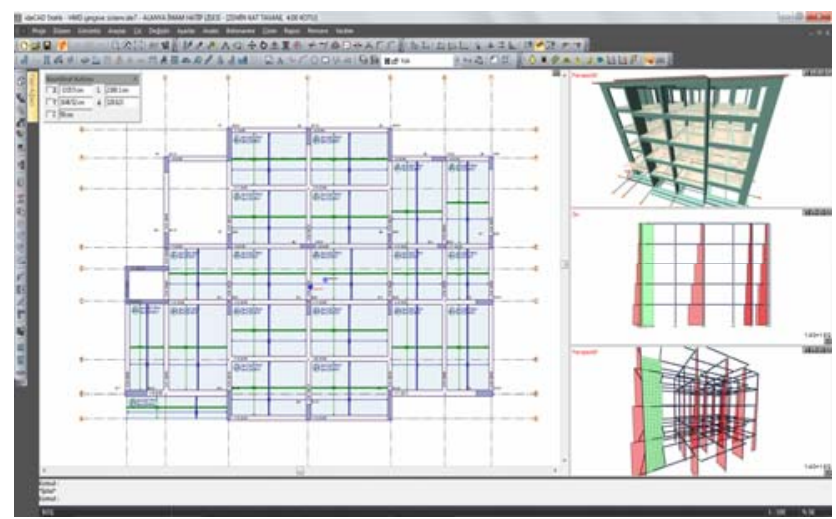

Figure 4. Normal Flooring

One of the greatest advantages of CAD programmers is that after necessary calculations are made, all the drawing layout belonging to the project produced automatically by the programmer are taken and they are prepared for approval by making necessary arrangements. Taking project layout quickly enables saving time and economy. A technician making necessary controls over the frame and bars plan can immediately decide whether there is a mistake or any problems in the results of quantity survey by examining. In the Figure 5, there exists the frame plan belonging to the ribbed floor slab. In the quantities belonging to the rib material considered to be made over the pattern plan brick or insulating block etc. can be immediately calculated according to the necessary measurements. In the Figure 6 there is Column Application Plan belonging to Normal Flooring. That all the bars drawings behaviors total and measurements belonging to the related column on the application plans are given enables great conveniences in the stage of construction. In the Figure 7, there are details of drawings belonging to $\mathrm{K} 103$ beam in the flooring system.

The education building was considered as both ribbed floor slab and normal flooring and the system analyses of it were made according to the available 2007 Turkey Earthquake Regulation [5], TS 498 [6] and TS 500 [7]. Calculations were made in the analyses considering the construction principles of earthquakeresistant and both two projects were transformed into the application projects. Both two projects were designed as a state that can be offered to the official institute. The image belonging to the ribbed floor slab system was given in Figure 3 and the image belonging to the normal flooring system was given in Figure 4.
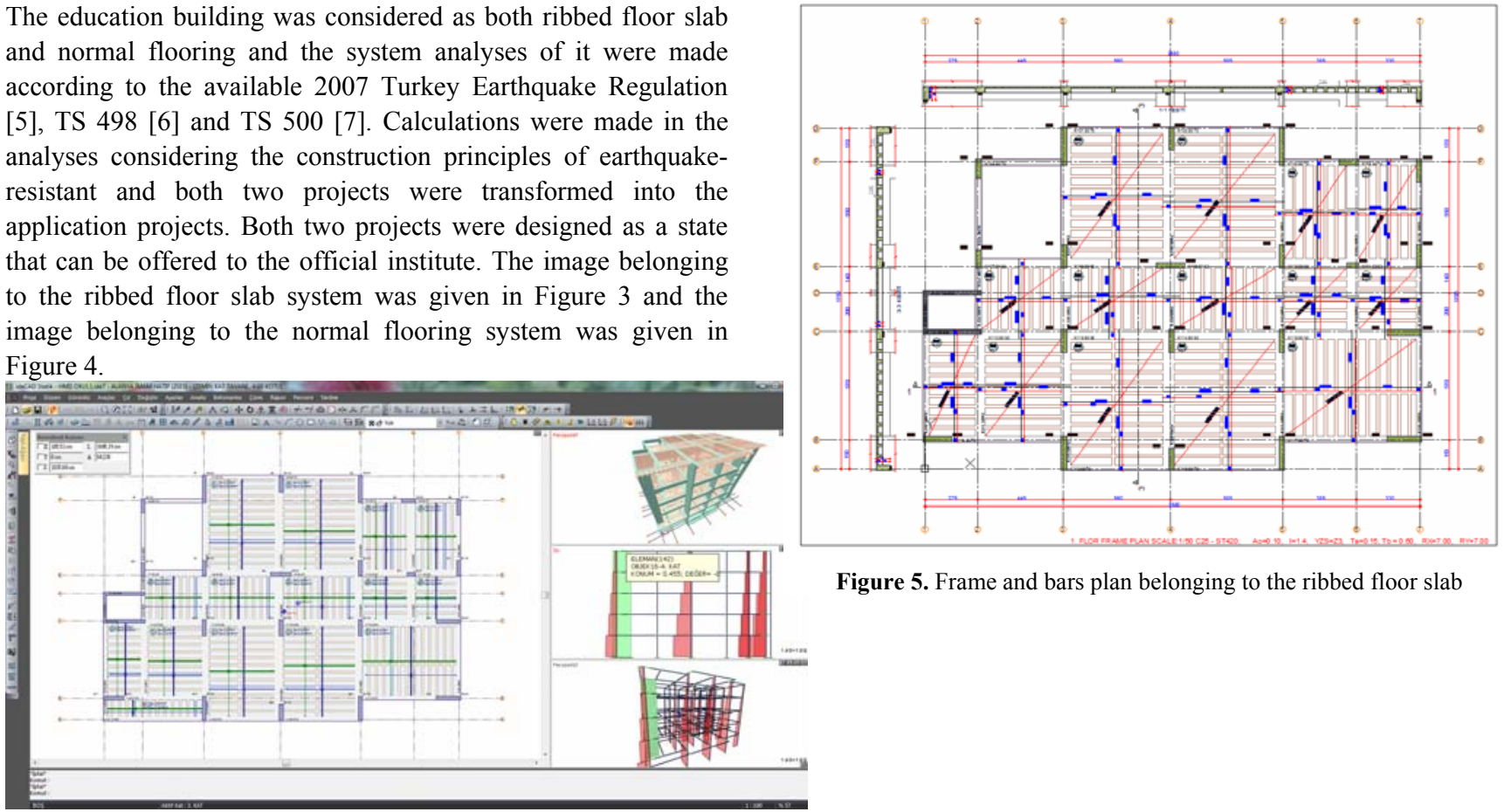

Figure 5. Frame and bars plan belonging to the ribbed floor slab

Figure 3. Ribbed floor slab 


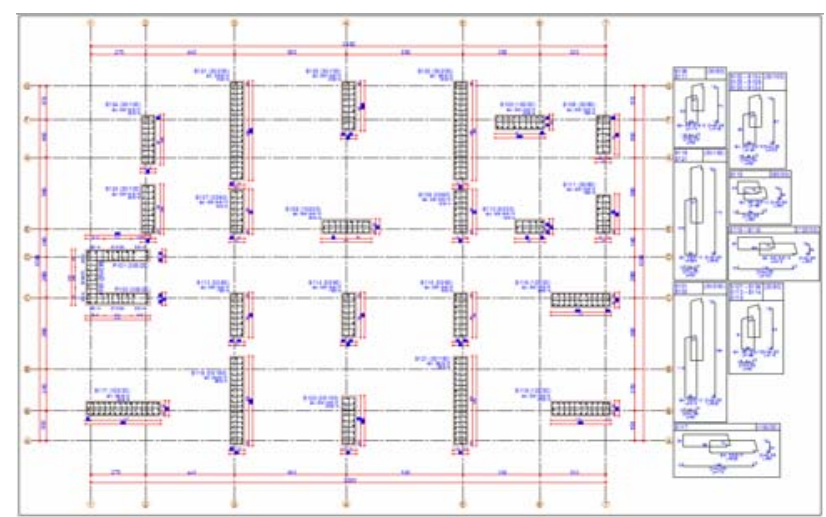

Figure 6. Column Application plan belonging to the normal flooring system
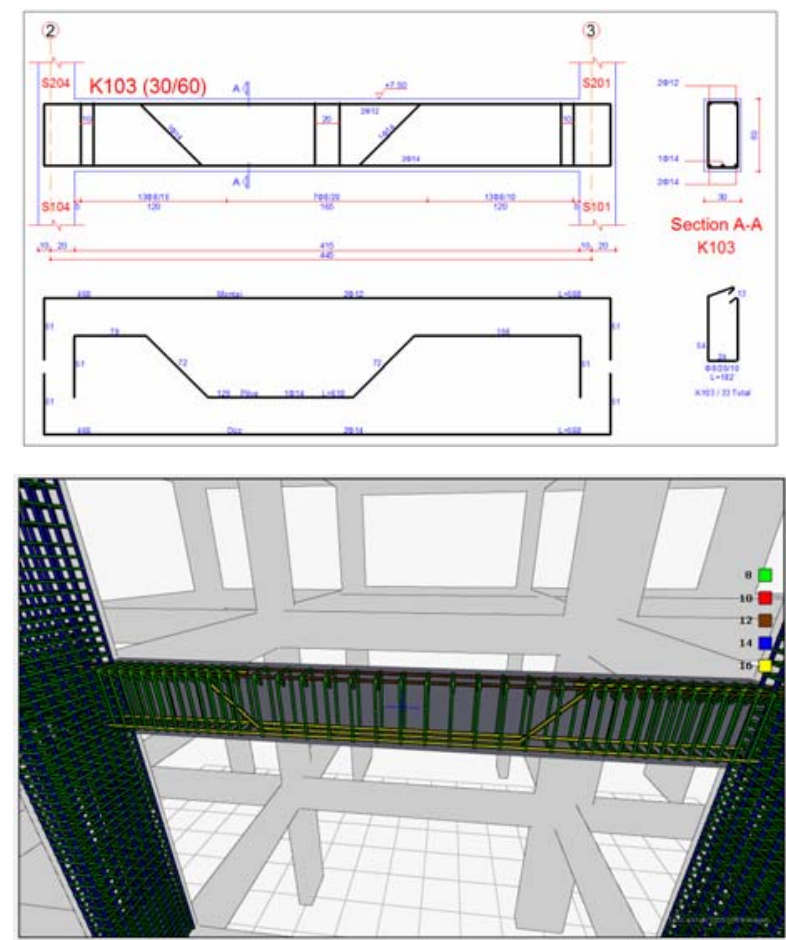

Figure 7. K103 Beam details belonging to the normal flooring system

The quantity survey of two projects were automatically taken from the CAD programmer and the prices of formworks, concrete and reinforcing bar were determined according to the unit prices that 2013 T.R. Ministry of Environment and Urban Planning published every year and according to the quantity survey obtained, their costs were found. In Table 1, the lists of quantity survey belonging to two buildings exist. In Table 2, pose number, definition and 2013 unit prices of the related unit prices exist [8].

Table 1. The quantity survey belonging to the education building and determined through CAD programmer

\begin{tabular}{cccc}
\hline $\begin{array}{c}\text { The Type of } \\
\text { Manufacturing }\end{array}$ & \multicolumn{2}{c}{ The Type of Bearing System } & Unit \\
\cline { 2 - 3 } & $\begin{array}{c}\text { Normal } \\
\text { Flooring }\end{array}$ & $\begin{array}{c}\text { Ribbed floor } \\
\text { slab }\end{array}$ & \\
\hline BS25 Concrete & 702.42 & 780.69 & $\mathrm{~m}^{3}$ \\
\hline $\begin{array}{c}\text { Concrete formwork } \\
\text { S420 reinforcing bar } \\
\text { (Total) }\end{array}$ & 4272.68 & 5832.30 & $\mathrm{~m}^{2}$ \\
\hline
\end{tabular}

Table 2. The List of the Ministry of Environment and Urban Planning High Science Chairman of the Board, Construction and Installment Analysis and the Unit of Prices

\begin{tabular}{|c|c|c|}
\hline Pos No & Definition & $\begin{array}{l}\text { Unit Price } \\
\text { (TL) }\end{array}$ \\
\hline Y.16.050/05 & $\begin{array}{c}\text { C 25/30 Pressure Resistance Class } \\
\text { Produced in the Concrete Station or } \\
\text { Bought and Pumped with the Concrete } \\
\text { pump }\end{array}$ & 115.60 \\
\hline 21.011 & $\begin{array}{c}\text { Flush-faced concrete or RC formwork } \\
\mathrm{m}^{2}\end{array}$ & 19.59 \\
\hline $23.001 / 1$ & $\begin{array}{l}\text { Definition: Thin RC reinforcing bar (Q } \\
\text { 8-12) mm (It was considered in the } \\
\text { thick reinforcing bar in the same pose) }\end{array}$ & $2,250.38$ \\
\hline
\end{tabular}

According to the quantity survey obtained and unit prices, related costs of the education building were separately calculated in terms of construction types and according to the construction types, their costs were calculated. In Table 3 , the cost calculations and results of the buildings were seen.

Table 3. The comparative calculation of costs belonging to the education building

\begin{tabular}{cccccc}
\hline $\begin{array}{c}\text { The Type } \\
\text { of } \\
\text { Manufacturing }\end{array}$ & $\begin{array}{c}\text { Unit } \\
\text { Price } \\
\text { (TL) }\end{array}$ & $\begin{array}{c}\text { Normal } \\
\text { Flooring } \\
\text { quantity }\end{array}$ & $\begin{array}{c}\text { Total } \\
\text { Price } \\
\text { (TL) }\end{array}$ & $\begin{array}{c}\text { Ribbed } \\
\text { floor } \\
\text { slab } \\
\text { quantity }\end{array}$ & $\begin{array}{c}\text { Total } \\
\text { Price } \\
\text { (TL) }\end{array}$ \\
\hline $\begin{array}{c}\text { BS25 } \\
\text { Concrete } \\
\left(\mathrm{m}^{3}\right)\end{array}$ & 115,60 & 702,42 & 81199,75 & 780,69 & 90247,76 \\
\hline $\begin{array}{c}\text { Concrete } \\
\text { formwork } \\
\left(\mathrm{m}^{2}\right)\end{array}$ & 19,59 & 4272,68 & 83701,80 & 5832,30 & 114254,76 \\
\hline $\begin{array}{c}\text { S420 } \\
\text { reinforcing bar } \\
(\text { Total) }(\mathrm{kg})\end{array}$ & 2,25 & 68037,07 & 153109,26 & 95923,18 & 215863,61 \\
\hline $\begin{array}{c}\text { Sum Total } \\
\text { Price } \\
(\mathrm{TL})\end{array}$ & & & 318010,81 & & \\
\hline
\end{tabular}

\section{Conclusion}

CAD programs have become indispensable of today's construction technologies. Official institutions made it an obligation that the projects are definitely prepared through CAD programmers. CAD programmers are important in terms of utilizing from the advantages such as accelerating the preparation stages of the projects and making the most appropriate cost analyses $[9,10]$

While the project of the education building that is examined is at the stage of preparation, it was processed to the cost analyses in two different types of flooring system and considering the quantity survey quantity of only concrete, formwork and reinforcing bar, calculations were made. According to the quantity survey calculation, while the cost of normal flooring system was determined as $318010.81 \mathrm{TL}$, the cost of ribbed floor slab system was determined as $420366.13 \mathrm{TL}$. In total, with the difference of construction systems, there is a difference of 102355.30 TL according to the quantity survey quantity taken from only 3 items. This difference means a difference of $25 \%$ and this can be said to be much meaningful when considered the limited opportunities of the country for an education building. A 
necessary came out that these cost analyses should be made in the design preparation stage of the project by considering these subjects in the construction systems. What is more, filler block costs for filler block flooring were not evaluated. When these costs are taken, it can be seen that the difference of cost will increase more.

\section{References}

[1] S. Kravanja and T. Žula, "Cost optimization of industrial steel building structures", Advances in Engineering Software 41 (2010) 442-450

[2] Yen-Liang Chen et all., "Building a cost-constrained decision tree with multiple condition attributes Tang “, Information Sciences 179 (2009) 967-979

[3] T.M.S. Elhag et all, "Critical determinants of construction tendering costs:Quantity surveyors_standpoint", International Journal of Project Management 23 (2005) $538-545$

[4] http://www.idecad.com/default.asp

[5] Turkish Earthquake Code (TEC). Regulations on structures constructed in disaster regions. Ankara: Ministry of Public Works And Settlement; 2007.

[6] TS 498, (1997), “ Design Loads for Buildings”, TSE, Ankara.

[7] TBC-500-(2000). Requirements for design and construction of reinforced concrete structures. Ankara: TSE; 2000.

[8] http://www.birimfiyat.com

[9] Altın M., "Contribution of Computer Aided Design Programs to the Perceptions of the Students of Construction Lessons in Construction Project Drafting and Techniques at Vocational Higher Schools", International Conference on New Trends in Education and Their Implications 11-13 November, 2010 Antalya-Turkey ISBN: 9786053641049

[10] Mustafa ALTIN and Şakir TAŞDEMIR, "Design and Construction of an Overpass with Computer-Aided Design Software and its Use in Construction Technology Education", Academic Journal of Science, ISSN: 21656282, Volume 01, Number 02 (2012), pp:15-20 http://universitypublications.net/ajs/0102/html/FIR576.xml 